\title{
Design of Micro-Transformer in Monolithic Technology for High Frequencies Fly-back Type Converters
}

\author{
Abdeldjebbar Abdelkader (D), Hamid Azzedine \\ Department of Electrical Engineering, USTO-MB University School of Engineering, Oran, Algeria
}

Cite this article as: A. Abdelkader, H. Azzedine, "Design of Micro-Transformer in Monolithic Technology for High Frequencies Fly-back Type Converters", Electrica, vol. 18, no: 2, pp. 325-332, 2018.

\begin{abstract}
This article describes the design of a micro-transformer in monolithic technology for high frequencies comprising planar type coil and a magnetic circuit made of several layers of materials. This micro-transformer is integrated into a micro-converter of fly-back type. The Mohan method was used to determine the geometric parameters and the S-parameters were used to calculate technological parameters. The study of electromagnetic effects allowed us to show the role of ferrite, which is used to confine the magnetic field lines and minimize disruption of the neighbor ship. To validate the dimensioning of the geometrical and technological parameters, with the help of the software PSIM6.0, we simulated the equivalent electrical circuit of the converter containing the electrical circuit of the dimensioned planar micro-transformer
\end{abstract}

Keywords: Fly-back converter, Planar Micro-Transformer, S-parameters, inductive elements, passive

\section{Corresponding Author:}

Abdeldjebbar Abdelkader

E-mail:

abdeljebar.aek9@gmail.com

Received: 16.02 .2018

Accepted: 10.05 .2018

(c) Copyright 2018 by Electrica

Available online at

http://electrica.istanbul.edu.tr

DOI: 10.26650/electrica.2018. 96182

\section{Introduction}

The passive components occupy $80 \%$ of the surface of a low-power converter. They have several roles, such as the temporary storage of electrical energy, filtering, electrical isolation, energy transfer as well as impedance matching. Today, only the integration of passive components is achievable, especially with inductive components. The barrier of integrating active components remains the most persistent obstacle that slows the rush to miniaturization [1, 2]. At the heart of isolated converters, there exists an essential element, the transformer. By reducing the dimensions, conventional coils are limited since they are wound with copper wire which prevents size reduction. The micro-transformers are formed from a thin magnetic circuit, usually made of ferrite, and on which conductive coils are inserted. The aim is to integrate the transformer in a micro-converter of flyback type for low voltages, low powers and high frequencies. The conception of a transformer goes through several phases: analysis of specifications, calculation and dimensioning of transformer parameters and validation by numerical simulation. In this work, the micro-transformer is presented under a form completely different to the geometric form of a classical transformer. This geometry is a square spiral and it adapts to the integrated technology $[3,4]$.

\section{Dimensioning of the Micro Transformer}

\section{Presentation of the Micro Transformer}

The micro converter fly-back presented in Figure 1, is the starting point for the design of passive components and especially, the micro transformer. This converter was chosen because it is composed of a transformer and few passive components. It operates in discontinuous conduction when the current demanded by the load is low, and in continuous conduction for higher currents. To produce such a device, we start with conventional transformer windings. To implement this function, it is necessary to have a magnetic core around 


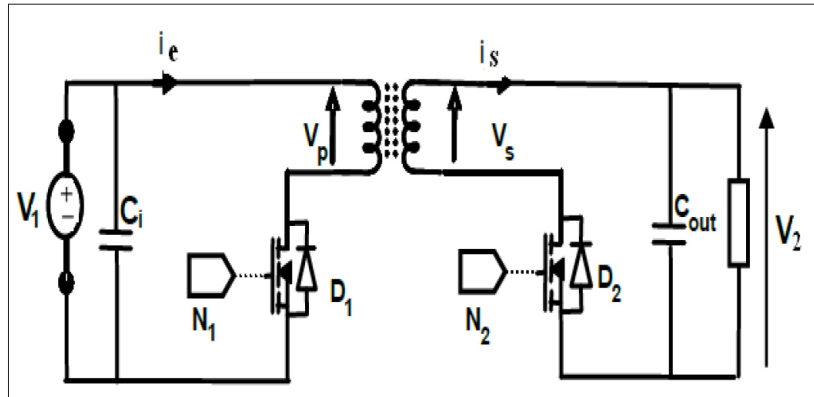

Figure 1. Schematic diagram of fly back converter [5]

Table 1. Characteristics of used materials

\begin{tabular}{lccc}
\hline Materiel & Copper & NiFe & SiO $_{2}$ \\
\hline Conductivity $\sigma(S / m)$ & $5,99.10^{7}$ & $2,2.10^{4}$ & 0 \\
\hline Resistivity $\rho(\Omega . \mathrm{m})$ & $1,7.10^{-8}$ & $20.10^{-8}$ & $10^{6}$ \\
\hline Relative Permittivity $\varepsilon_{\mathrm{r}}$ & 1 & 10 & 3,9 \\
\hline Relative permeability $\mu_{\mathrm{r}}$ & 1 & 800 & 1 \\
\hline
\end{tabular}

which the primary and secondary windings are placed. This transformer, due to the magnetic coupling, naturally induces the effects of leakage mainly related to the choice of placement of windings.

\section{The Specifications of the Micro-Converter}

We selected the following set of specifications: Input voltage $\mathrm{V}_{\text {in }}=10 \mathrm{v}$, Output voltage $\mathrm{V}_{\text {out }}=4 \mathrm{v}$ Current output means Is $=1.5 \mathrm{~A}$

Average power Ps $=6 \mathrm{~W}$, Operating frequency $\mathrm{f}=40 \mathrm{MHz}$

\section{The Characteristics of the Materials Used}

The Table 1 below shows the characteristics of the materials constituting the coil layers.

It shows the different geometric and electrical parameters that constitute the micro transformer Figure 2 [6]. A core with a square form for the windings has been chosen due to the limitation of surface and volume.

\section{Dimensioning of the Magnetic Circuit}

From the specifications, we define the characteristics of the micro-converter which is the starting point for the design of micro-transformer. It consists of two inductors placed on a magnetic material and separated by a dielectric, which also provides magnetic coupling. The values of the frequency $f$ and the input voltage $V_{e}$ allow us to calculate the value of the primary and secondary inductances $L_{t}$ and $L_{b}$ of our transformer $[7,8]$.

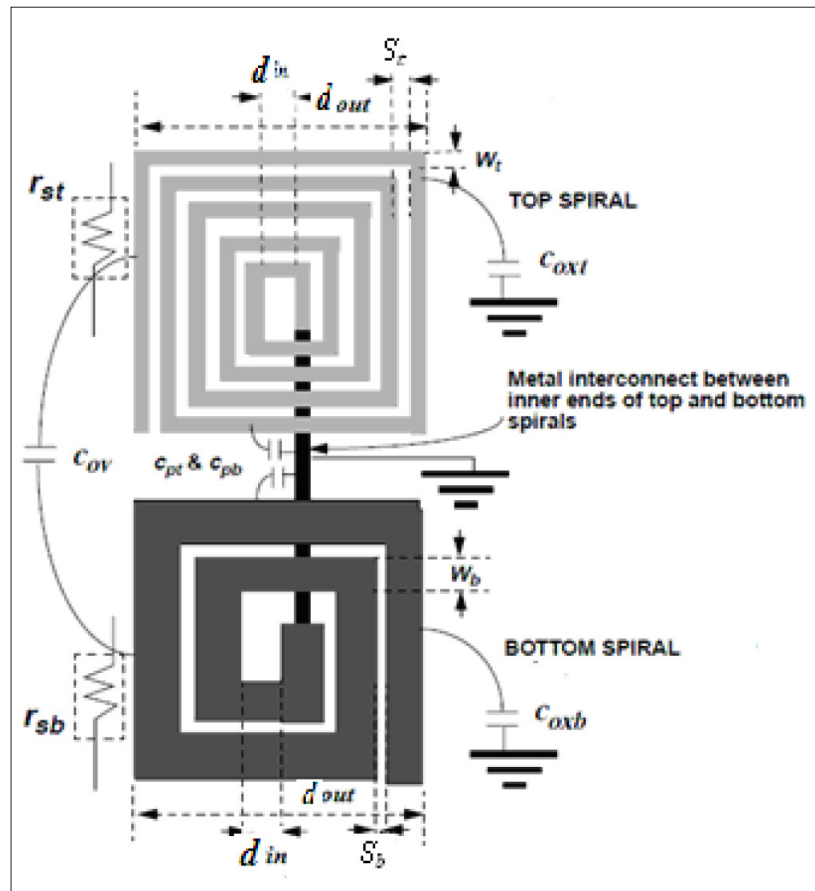

Figure 2. The different parameters characterizing the micro-transformer [7]

$L_{t}=\frac{V_{e}^{2} \alpha^{2}}{2 f P_{s}} \quad L_{b}=m^{2} L_{t}$

$m=\frac{1-V_{s} \alpha}{\alpha V_{e}}$

m: turn ratio $=0.4, L_{t}=52 \mathrm{nH}$ and $L_{b}=8.3 \mathrm{nH}$

\section{Calculation of the Energy Stored In The Magnetic Core}

The dimensioning of the magnetic core depends on the volume required to store energy which is calculated from the volumetric energy density given by equation (3) [9].

$W=\frac{1}{2} L_{t} i_{e}^{2}=\frac{1}{2} L_{b} i_{s}^{2}=937.10^{-9} j$

\section{Calculation of the Volume Density Of Energy}

To determine the volume $V$ of permalloy (NiFe) necessary for this storage, we need to know the volume density of energy of this material. This volume $\mathrm{V}$ is given by relationship (4) [10].

$V=\frac{W}{W_{\max }} \quad W_{\max }=\frac{B_{\max }^{2}}{2 \mu_{0} \mu_{r}}$ 


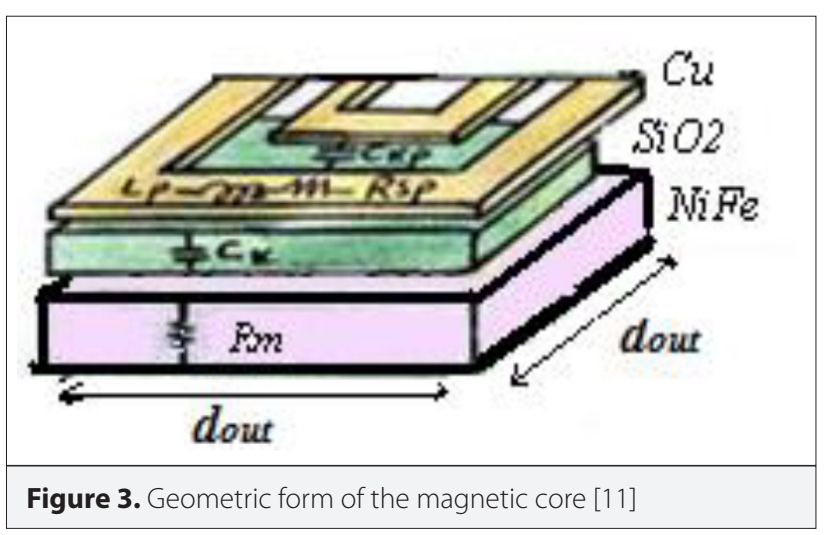

With a relative permeability $\mu_{r}=800$ and saturation induction $B_{\max }=0.6 \mathrm{~T}$ of permalloy, we obtain: $W_{\max }=179 \mathrm{jm}^{-3}$, and $V=0.052 \mathrm{~mm}^{3}$ of Nife is needed to store $0.937 \mu \mathrm{J}$.

\section{Core Dimensions}

With the volume of the ferromagnetic core being evaluated as $V=0.052 \mathrm{~mm}^{2}$, the core as a block is considered as having a thickness of $e_{\text {Nife }}$ and a section of $A=d_{\text {out }}{ }^{2}, S$ is the section on which we will put the spiral coil. To define the dimensions of the core see Figure $3, d_{\text {out }}=1800 \mu \mathrm{m}$ was opted for and we section $A$ and the thickness core $e_{\text {Nife }}$ was calculated by using equation "7" $A=324.10^{4} \mu \mathrm{m}$

$e_{\text {Nife }}=\frac{V}{A}=16.15 \mu m$

\section{Calculating of Turn's Number}

The primary and secondary values of inductance are given by the following formulas (method Mohan) [12, 13].

$L_{t}=\frac{\mu . . n_{t}^{2} \cdot D_{m o y} \cdot C_{1}}{2}\left(\ln \left(\frac{C_{2}}{\rho}\right)+\rho \cdot C_{3}+\rho^{2} C_{4}\right)$

$L_{b}=\frac{\mu . n_{b}^{2} \cdot D_{\text {moy }} \cdot C_{1}}{2}\left(\ln \left(\frac{C_{2}}{\rho}\right)+\rho \cdot C_{3}+\rho^{2} C_{4}\right)$

$D_{\text {moy }}$ is the average diameter of the inductor defined from the inner diameter and outer diameter $d_{\text {out }}$ and $d_{\text {in }}$ equation (8) [14].

$D_{\text {moy }}=\frac{d_{\text {out }}+d_{\text {in }}}{2}=1350 \mu \mathrm{m}$

$\rho$ is the form factor, defined by relationship " 9 "

$\rho=\frac{d_{\text {out }}-d_{\text {in }}}{d_{\text {out }}+d_{\text {in }}}=0.33$
$C_{1^{\prime}} C_{2^{\prime}} C_{3^{\prime}} C_{4}$ are the constants of Mohan given by Table 2.

Table 2. The constants of mohan

\begin{tabular}{lcccc}
\hline Geometry & $\mathbf{C}_{\mathbf{1}}$ & $\mathbf{C}_{\mathbf{2}}$ & $\mathbf{C}_{\mathbf{3}}$ & $\mathbf{C}_{\mathbf{4}}$ \\
\hline Square & 1.27 & 2.07 & 0.18 & 0.13 \\
\hline
\end{tabular}

The primary and secondary turn's numbers are calculated by using expressions 10 and 11

$$
n_{t}=\sqrt{\frac{2 L_{t}}{\mu . D_{m o y} \cdot C_{1}\left(\ln \left(\frac{C_{2}}{\rho}\right)+\rho \cdot C_{3}+\rho^{2} C_{4}\right)}}
$$

$$
n_{b}=\sqrt{\frac{2 L_{b}}{\mu . D_{m o y} \cdot C_{1}\left(\ln \left(\frac{C_{2}}{\rho}\right)+\rho \cdot C_{3}+\rho^{2} C_{4}\right)}}
$$

After calculation, we find: $n_{t}=5, n_{b}=2$

\section{Calculating the width of the primary and secondary conductors}

To eliminate the skin effect so that the electrical current is distributed over the entire section of the conductor, one of the following conditions must be satisfied: $W \leq 2 \delta$ or $\mathrm{t} \leq 2 \delta$

Where $\mathrm{w}$ and $\mathrm{t}$ the width and thickness of the conductor. For $\mathrm{a}$ frequency $\mathrm{f}=40 \mathrm{MHz}, \rho_{\text {copper }}=1.7 .10^{-8}[\Omega . \mathrm{m}]$ and $\mu_{r}=1[\mathrm{H} / \mathrm{m}]$ a skin thickness $\delta$ is obtained by used of equation "12", [15].

$\delta=\sqrt{\frac{\rho}{\pi \cdot \mu_{0} \cdot f}}=10.38 \mu \mathrm{m}$

We impose one of two values $W$ or $t$ and compute the second. It is preferable to impose the value of the thickness " $t$ " of the conductor, since the width $W$ should be optimized to reduce the parasitic effects linked to the substrate and the core. By assigning to " $\mathrm{t}$ " a value that verifies $\leq 2 \delta$, the width can be calculated by the use of equation (13).

$$
S=W . t
$$

When a current $I$ flows in a conductor of section $S$ its current density $J_{a v g}$ is given by expression (14).

$I=S . J_{\text {avg }}$

$j_{\text {avg }}=\frac{1}{\delta} \int_{0}^{\delta} j(w) d w=\frac{1}{\delta} \int_{0}^{\delta} j_{0} e^{\frac{-w}{\delta}} d w=j_{0}\left(1-e^{-I}\right) \approx 0.63 j_{0}$ 
In most cases, the micro-wires are in contact with a semiconductor substrate that has good heat conduction properties. This allows boundary conditions of $J_{o}=10^{9} \mathrm{~A} / \mathrm{m}^{2}$ [14].

by considering the same surface current density in the two windings, and the same thickness value of the primary and secondary conductors $t$, we obtain the following results. Results are obtained by putting $t=20.76 \mu m, W_{t}$ and $W_{b}$

\section{Calculation of primary and secondary Inter-turn's spacing} $S_{t}$ and $S_{b}$

$S_{t}=\left(d_{\text {out }}-d_{\text {in }}-2 W_{t} \cdot n_{t}\right) / 2\left(n_{t}-1\right)$

$S_{b}=\left(d_{\text {out }}-d_{\text {in }}-2 W_{b} . n_{b}\right) / 2\left(n_{b}-1\right)$

\section{Calculation of primary and secondary Conductor length}

$l_{t}=4 . n_{t}\left(d_{\text {out }}-\left(n_{t}-1\right) \cdot S_{t}-n_{t} \cdot W_{t}\right)-S_{t}$

$l_{b}=4 . n_{b}\left(d_{\text {out }}-\left(n_{b}-1\right) . S_{b}-n_{b} . W_{b}\right)-S_{b}$

All parameters that go into the design of the micro-transformer are represented in the summary Table 3 below.

The results ontained are in agreement with integration, because the values of the different geometric parameters are within the recommended dimensions for the integration in low power electronics.

Table 3. Values of the geometrical parameters

\begin{tabular}{lc}
\hline Geometrical parameters & Values \\
\hline Outer diameter: $d_{\text {out }}$ & $1800 \mu \mathrm{m}$ \\
\hline Inner diameter: $d_{i n}$ & $900 \mu \mathrm{m}$ \\
\hline Core thickness: $e$ & $16.15 \mu \mathrm{m}$ \\
\hline Skin thickness: $\delta$ & $10.38 \mu \mathrm{m}$ \\
\hline Number of primary turns: $n_{t}$ & 5 \\
\hline Number of secondary turns: $n_{b}$ & 2 \\
\hline Width of the primary $W_{t}$ & $45 \mu \mathrm{m}$ \\
\hline Width of the secondary: $W_{b}$ & $196.87 \mu \mathrm{m}$ \\
\hline Thickness of the primary: $t_{t}$ & $20.76 \mu \mathrm{m}$ \\
\hline Thickness of the secondary: $t_{b}$ & $20.76 \mu \mathrm{m}$ \\
\hline Primary spacing: $S_{t}$ & $56.25 \mu \mathrm{m}$ \\
\hline Secondary spacing: $S_{b}$ & $56.25 \mu \mathrm{m}$ \\
\hline Primary total length: $I_{t}$ & $2.7 \mathrm{~cm}$ \\
\hline Secondary total length: $I_{b}$ & $1.07 \mathrm{~cm}$ \\
\hline
\end{tabular}

\section{Modeling of Micro Transformer}

The use of S-parameters will help to determine the values of the primary and secondary inductances, the primary and secondary series resistors and the quality factor. The calculation with the S-parameters is made from the $\pi$-electric model of the micro-transformer "Figure 4".

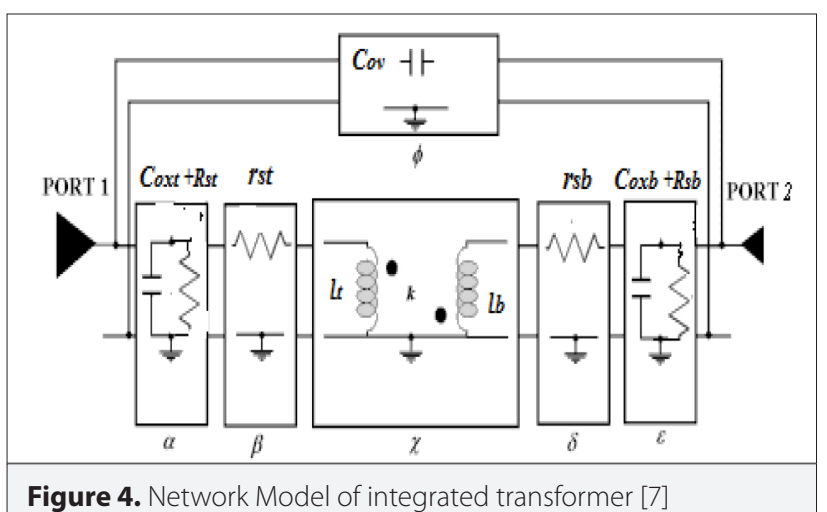

$S_{11^{\prime}} S_{12^{\prime}} S_{21^{\prime}} S_{22}$ are the $S$ parameters. $Z_{0}=50 \Omega$ is the characteristic impedance of the line.

From the low-frequency S-parameters, the Z-parameters at each frequency point are determined. This can be shown as follows:

$Z_{11}=Z_{0} \frac{\left(1+S_{11}\right) \cdot\left(1-S_{22}\right)+S_{21} \cdot S_{12}}{\left(1-S_{11}\right) \cdot\left(1-S_{22}\right)-S_{12} \cdot S_{21}}$

$$
\begin{gathered}
Z_{21}=Z_{12}=Z_{0} \frac{2 \cdot S_{12}}{\left(1-S_{11}\right) \cdot\left(1-S_{22}\right)-S_{12} \cdot S_{21}} \\
Z_{22}=Z_{0} \frac{\left(1+S_{11}\right) \cdot\left(1-S_{22}\right)+S_{21} \cdot S_{12}}{\left(1-S_{11}\right) \cdot\left(1-S_{22}\right)-S_{12} \cdot S_{21}}
\end{gathered}
$$

From these equations we find the variables that make up the model Pi shown in "Figure 4" and the inductances of the primary $L_{t}$ and secondary $L_{b}$. These inductances are taken from the imaginary part of the impedances, are expressed by expression (20) $[16,17]$.

$L_{t}=\frac{\operatorname{Im}\left(Z_{11}\right)}{\omega} \quad L_{b}=\frac{\operatorname{Im}\left(Z_{22}\right)}{\omega}$

And series resistors of the integrated inductors $r_{s t}$ primary and $r_{s b}$ secondary are extracted from the real part of the impedances and are expressed by expression " 21 "

$$
r_{s t}=\operatorname{Re}\left(Z_{11}\right) \quad r_{s b}=\operatorname{Re}\left(Z_{22}\right)
$$


The expressions of quality factors extracted from the real and imaginary part of the impedances are given by expressions " 22 "

$Q_{t}=\frac{\operatorname{Im}\left(Z_{11}\right)}{\operatorname{Re}\left(Z_{11}\right)} \quad Q_{b}=\frac{\operatorname{Im}\left(Z_{22}\right)}{\operatorname{Re}\left(Z_{22}\right)}$

The transformer model Figure 5 is similar to the model of a spiral inductor. Indeed, the transformer is simply a pair of spiral inductor magnetically coupled. This model includes the series inductances of the primary and secondary coils $\left(L_{t}, L_{b}\right)$, the series resistances of second primary coil $\left(r_{s t} r_{s b}\right)$, the coupling capacitances between the turns $\left(C_{o v 1,2}\right)$, the capacities between the secondary and primary coils and the substrate $\left(C_{o x t^{\prime}} C_{o x b}\right)$, the substrate capacity of primary and secondary coils $\left(C_{s t^{\prime}} C_{s b}\right)$

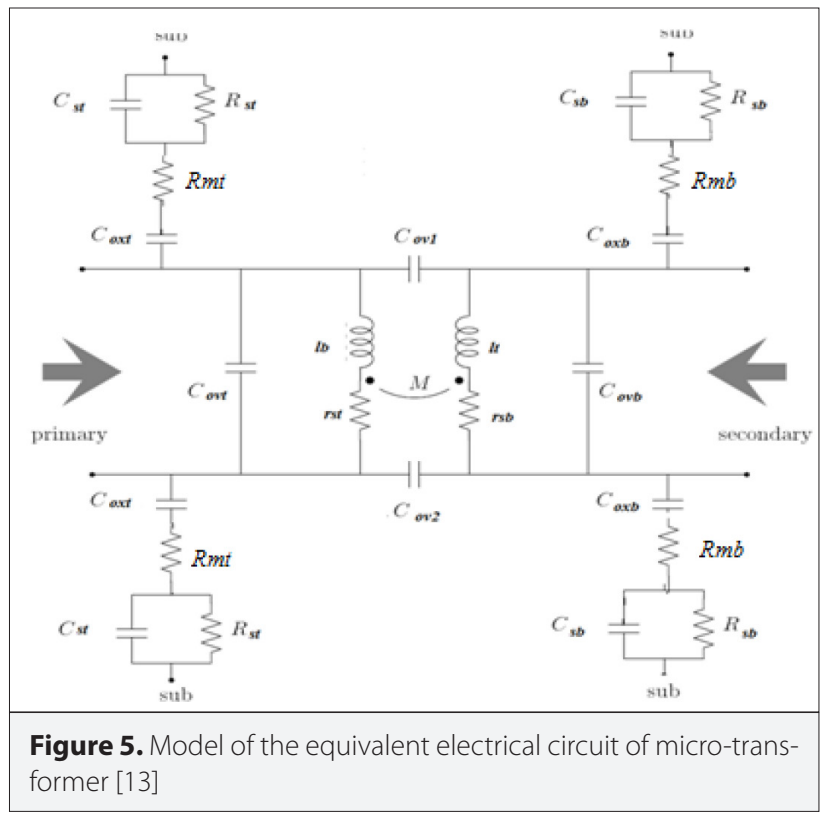

\section{Calculation of the Electrical Parameters}

Presented now are the analytical expressions of the electrical circuit's different elements [7].

The series resistance: $r_{s t} r_{s b}$

$r_{s t}=\frac{\rho \cdot l_{t}}{W_{t} . \delta .\left(1-e^{\frac{t}{\delta}}\right)} \quad r_{s b}=\frac{\rho \cdot l_{b}}{W_{b} . \delta \cdot\left(1-e^{\frac{t}{\delta}}\right)}$

The oxide capacities: $C_{o x t^{\prime}} C_{o x b}$

$c_{o x t}=\frac{. \varepsilon_{o x}}{2 \cdot t_{o x, t}} \cdot W_{t} \cdot l_{t} \quad c_{o x b}=\frac{. \varepsilon_{o x}}{2 \cdot t_{o x, b}} \cdot W_{b} \cdot l_{b}$

The coupling capacitance between the turns $C_{\text {ovt }}, C_{\text {ovb }} C_{\text {ov1,2 }}$ : $c_{o v t}=\frac{\varepsilon_{o x}}{2 . S_{t}}\left(t_{t} \cdot l_{t}\right) c_{o v b}=\frac{\varepsilon_{o x}}{2 . S_{b}}\left(t_{b} \cdot l_{b}\right)$

$c_{o v 1}=\frac{\varepsilon_{o x} \cdot W_{t} \cdot l_{t}}{t_{o x}} \quad c_{o v 2}=\frac{\varepsilon_{o x} \cdot W_{b} \cdot l_{b}}{t_{o x}}$

The substrate capacity of primary and secondary coils: $C_{s t} C_{s b:}$

$c_{s t}=\frac{\varepsilon_{s i} \cdot l_{t} \cdot W_{t}}{2 \cdot e_{s i}} c_{s b}=\frac{\varepsilon_{s i} \cdot l_{b} \cdot W_{b}}{2 \cdot e_{s i}}$

The substrate resistance of the primary and secondary coils: $R_{s t^{\prime}} R_{s b}$

$R_{s t}=\frac{2 \cdot \rho_{s i} \cdot e_{s i}}{l_{t} \cdot W_{t}} \quad R_{s b}=\frac{2 \cdot \rho_{s i} \cdot e_{s i}}{l_{b} \cdot W_{b}}$

$R_{m t}=\rho_{\text {Nife }} \frac{e_{\text {Nife }}}{l_{t} \cdot W_{t}} \quad R_{m b}=\rho_{\text {Nife }} \frac{e_{\text {Nife }}}{l_{b} \cdot W_{b}}$

\subsection{Results of Electrical Parameter's Calculation}

The Table 4 summarizes the different calculated electrical parameters.

Table 4. Values of micro-transformer's electrical parameters

\begin{tabular}{lc}
\hline Electrical parameters & Values \\
\hline primary inductance $L_{t}$ & $52 \mathrm{nH}$ \\
\hline secondary inductance $L_{b}$ & $8.3 \mathrm{nH}$ \\
\hline Primary serial resistance $r_{\text {st }}$ & $1.11 \Omega$ \\
\hline Secondary serial resistance $r_{\text {sb }}$ & $0.10 \Omega$ \\
\hline Primary oxide capacitance $C_{\text {oxt }}$ & $2.96 \mathrm{pF}$ \\
\hline Secondary oxide capacitance $C_{\text {oxb }}$ & $5.08 \mathrm{pF}$ \\
\hline Primary résistance of substrate $R_{\text {st }}$ & $2.99 \mathrm{~K} \Omega$ \\
\hline Secondary résistance of substrate $R_{\text {sb }}$ & $1.74 \mathrm{~K} \Omega$ \\
\hline Primary capacitance of du substrat $C_{\text {st }}$ & $0.64 \mathrm{pF}$ \\
\hline Secondary capacitance of substrate $C_{\text {sb }}$ & $1.10 \mathrm{pF}$ \\
\hline Capacitance inter-spacing of primary $C_{\text {ovt }}$ & $0.16 \mathrm{pF}$ \\
\hline Capacitance inter-spacing of secondary $C_{\text {ovb }}$ & $0.064 \mathrm{pF}$ \\
\hline Coupling capacitance between the primary and & $5.45 \mathrm{pF}$ \\
secondary coils $C_{\text {ov1 }}$ & \\
\hline Coupling capacitance between the secondary & $10.05 \mathrm{pF}$ \\
and primary coils $C_{\text {ov }}$ & \\
\hline Primary magnetic resistance Rmt & $5.22 \mu \Omega$ \\
\hline Secondary magnetic resistance Rmb & $3.04 \mu \Omega$ \\
\hline
\end{tabular}




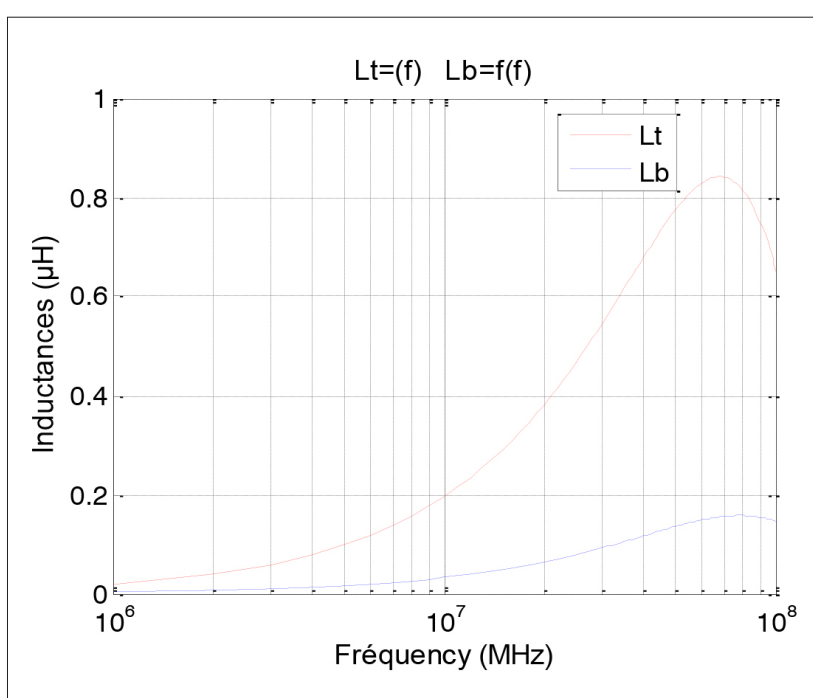

Figure 6. Influence of the operating frequency on the value of $L_{t}$ and $L_{b}$ inductors

\section{The Influence of Frequency on the Inductances of the Pri-} mary and Secondary

"Figure 6" shows the influence of the frequency on the inductances of the primary $L_{t}$ and secondary $L_{b}$. These inductances are extracted from the imaginary part of the impedances and are given by the expressions (20).

The figure above shows two distinct zones specific to the operation of the integrated inductors (primary and secondary). At the operating frequency $(40 \mathrm{MHz})$, the inductive behavior is recognized. Beyond the resonance frequency $(80 \mathrm{MHz})$, it is the capacitive behavior.

\section{Influence of Frequency on the Series Resistances of the Pri- mary and Secondary}

"Figure 7" shows the influence of the frequency on the series resistors $r_{s t}$ of primary and $r_{s b}$ of secondary. These resistances are extracted from the real part of the impedances and are expressed as (21).

The resistances $r_{s t}$ and $r_{s b}$ have very low values at the operating frequency $(40 \mathrm{MHz})$, so the losses by Joule effects are very low. At resonance, the primary and secondary series resistances result in a peak.

\section{Influence of Frequency on the quality Factor of Primary and Secondary Inductances}

"Figure 8 " shows the influence of the frequency on the quality factors of inductors primary and secondary. The expressions of quality factors extracted from the real and imaginary impedances are given by the expression " 22 ".

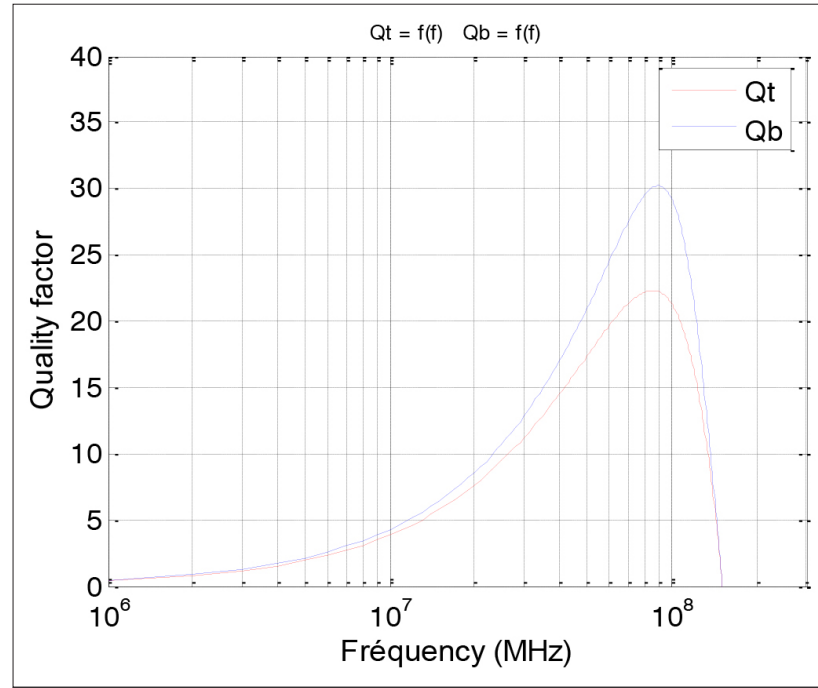

Figure 7. Influence of primary and secondary series resistance versus frequency

\section{Simulation of the Equivalent Electrical Circuit}

Simulations were conducted to determine the influence of losses on the micro converter. The PSIM 6.0 software has been selected to simulate the operation of the converter. The following three electrical parameters of the micro converter had to be calculated [10].

Load resistance of the Fly-back converter

$R_{s}=\frac{V_{s}}{i_{s}}=2.66 \Omega$

Capacity of the fly-back converter, for a voltage undulation equal to $0.01 \mathrm{~V}$, the capacitor $\mathrm{C}$ is equal to:

$C_{s}=\frac{\alpha^{2} m V_{e}}{(1-\alpha) \Delta V_{s} R_{s} f}=1.87 \times 10^{-6} \mathrm{~F}$

Magnetizing inductance

$L_{m}=n_{t}^{2} \frac{\mu_{\text {Nife }} d_{\text {out }}^{2}}{2 e} \approx 2.5 \mathrm{mH}$

\section{The integrated Transformer}

The transformer that we will be placed in the converter is lossless (integrated). Now the equivalent circuit of the converter containing the micro transformer is simulated.

The electrical circuit of the assembly is given in Figure 9.The simulation of voltages and currents are calculated by using the PCIM6.0 software. 


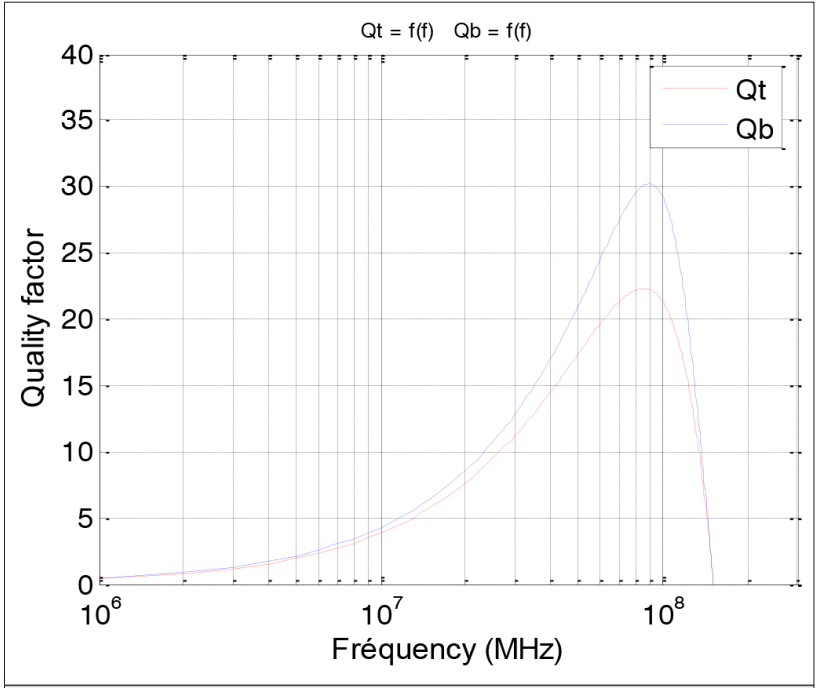

Figure 8. Quality factor of primary and secondary versus frequency

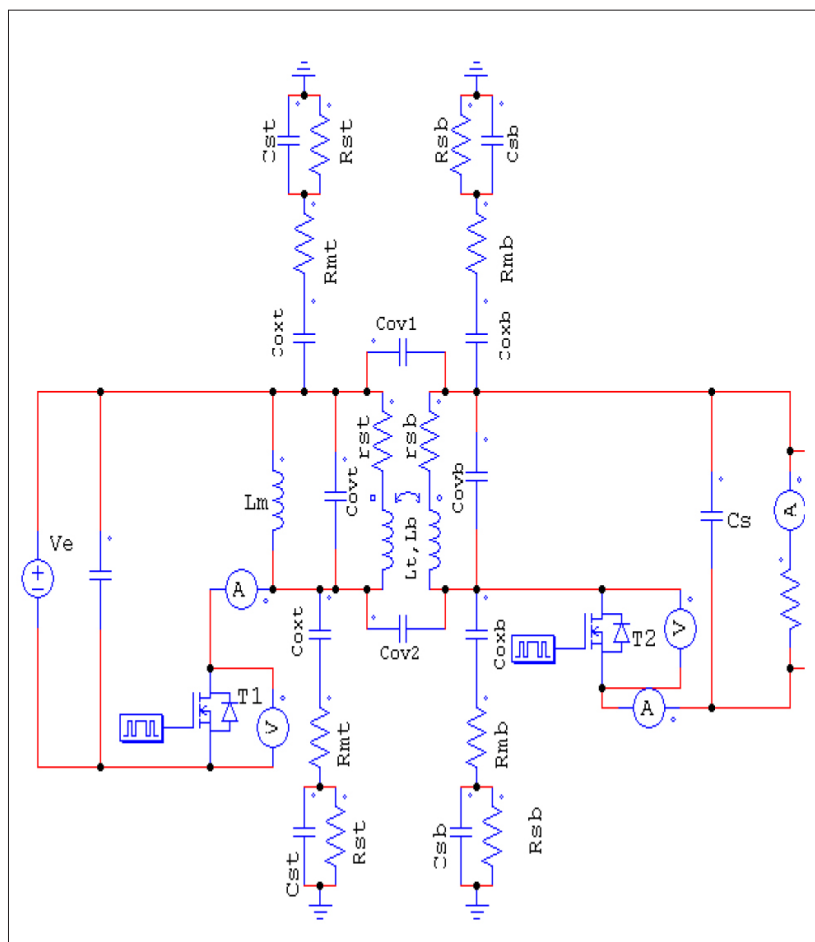

Figure 9. Equivalent electrical circuit of the micro converter containing the integrated transformer

For the integrated transformer, the results Figure 10 are encouraging because a continuous output voltage and a continuous output current are obtained and their values are very close to those of the specifications $(\mathrm{Vs}=4.2 \mathrm{~V}$ and $\mathrm{Is}=1.6 \mathrm{~A})$.

Therefore, it can be concluded that the geometrical dimensioning of the transformer gave good results.

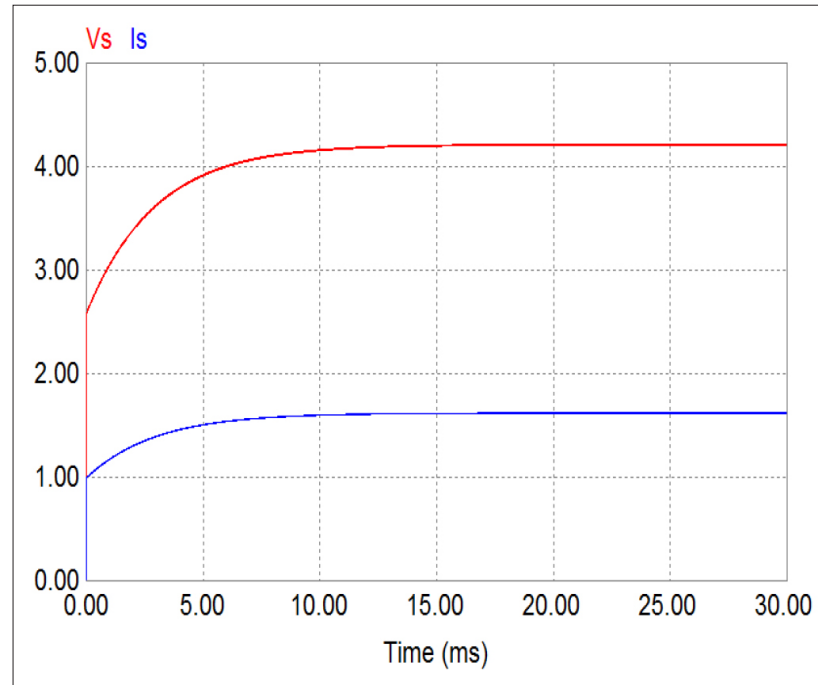

Figure 10. Output voltage of the micro converter containing the integrated transformer

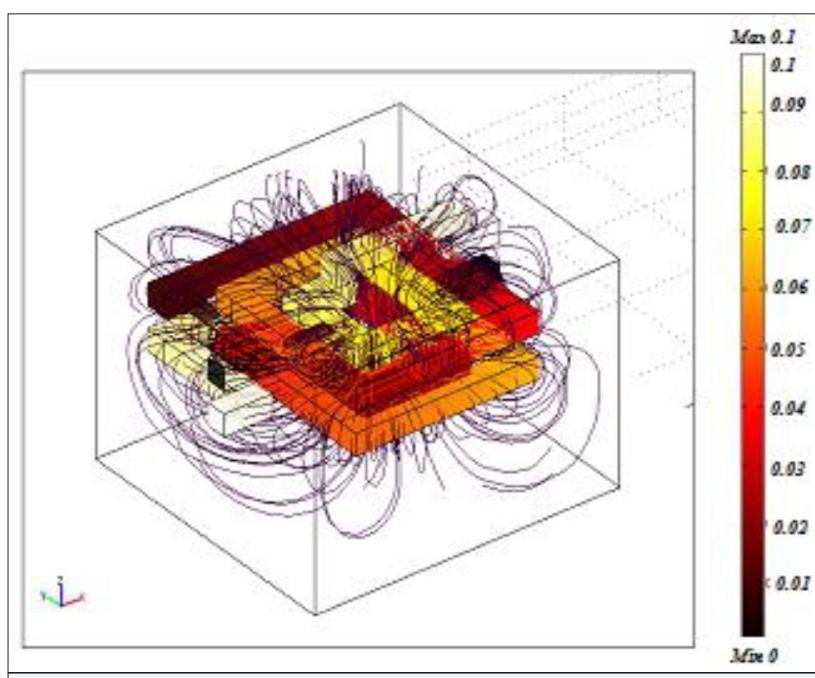

Figure 11. Magnetic field distribution in the micro-transformer without magnetic core

\section{Simulation of Different Effects on the Micro Transformer}

In this section, we the distribution of magnetic field lines in the micro-coils of the micro transformer will be presented.

Using the FEMLAB 3.1 software, an overflow of the magnetic field lines in all directions can be observed in Figure 11. These lines occupy all the space and are stopped only by the simulation boundaries of a coil in the air. This distribution can induce disturbances of the components located in the immediate vicinity of the micro transformer.

In Figure 12, the coils are deposited on a magnetic core, the majority of these field lines being confined in this core. This is explained by the high permeability of ferrite. The insertion of 


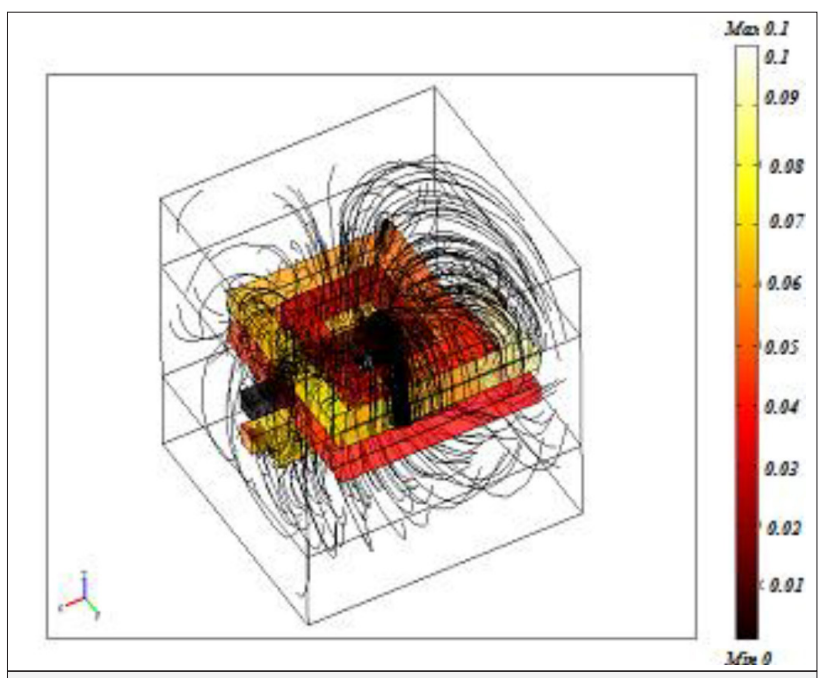

Figure 12. Magnetic field distribution in the micro-transformer with a magnetic core

the ferrite layers thus makes it possible to increase the number of magnetic field lines and to limit their overflow.

\section{Conclusion}

The aim of this study is to integrate the geometrical dimensioning of a micro-transformer and its electromagnetic modeling, into a micro-converter. This micro-transformer is intended for the field of mobile and embedded electronics requiring a conversion of energy of low power and a very high frequency range. The integrated micro-transformer is composed of several stacked layers, namely: two copper square planar coil windings, insulating layers, layers of ferrite magnetic material and a semiconductor layers.

As a starting point for this study, the specifications of the flyback type micro-converter was chosen. In the second part, according to the operating conditions of the system based on the method of Mohan, the geometrical dimensioning of the planar transformer was carried out.

In the third part, the geometric parameters to extract the various electrical parameters were used. In the last step, we integrated the dimensioned micro-transformer into a micro-converter. This step facilitated the testing of the operation of the micro-transformer. In order to validate our results, a simulation with PSIM6.0 was pwerformed using FEMLAB 3.1 simulation software to visualize the dispersion of the magnetic field lines for two different transformer models, a model with a core, and the second without a core.

\section{Peer-review: Externally peer-reviewed}

Conflict of Interest: The authors declared that this study has received no financial support.

Financial Disclosure: The authors declared that this study has received no financial support.

\section{References}

1. K. Youssouf, "Modélisation des transformateurs planaires intègres. Optics Photonic", Université Jean Monnet-Saint- Etienne, France, 2014.

2. D. D. Yaya, "Conception, réalisation et caractérisation d'inductances planaires à couches magnétiques", Université Jean Monnet-Saint-Etienne, France, 2013.

3. B. Vallet, «Étude et conception d'une nouvelle alimentation à découpage à transfert d'énergie mixte basée sur un composant passif LCT intégré" Université Joseph Fourier, 2008.

4. A. Besri, "Modélisation analytique et outils pour l'optimisation des transformateurs de puissance haute fréquence planars", Université de Grenoble, 2011.

5. T. H. Trinh, "Réseaux de micro convertisseurs, les premiers pas vers le circuit de puissance programmable", Energie électrique, Université de Grenoble, 2013.

6. R. Melati, A. Hamid, F. Baghdad, F. Taibi, "Simulation d'une micro bobine", 4ème Conférence Internationale sur l'Electrotechnique, Oran, Algeria, 2009.

7. S. Verma, J. M. Cruz, "On-chip Inductors and Transformers", Bibliometrics, 1999.

8. F. K. Wong, B. Eng, M. Phil, “High Frequency Transformer for Switching Mode Power Supplies", School of Microelectronic Engineering, Faculty of Engineering and Information Technology, Griffith University, Brisbane, Australia, 2004.

9. V. Boyer, N. Godefroy, "Alimentation à découpage Flyback”, M1-IUP GEII, Université Joseph Fourier IEEE.

10. M. Derkaoui, A. Hamid,T. Lebey, R. Melati, “Design and Modeling of an Integrated Micro-Transformer in a Flyback Converter", TELKOMNIKA, vol. 11, no. 4, pp. 669-682, 2013.

11. D. M. Pozar "Microwave Engineering", ${ }^{2 n d}$ Edition, Johnwiley and Sons Inc., 1998, pp.19-20, pp. 182-250.

12. S. Mohan, C.P. Yue, M. Del Mar Hershenson, S. Wong, T.H. Lee, "Modeling and characterization of on-chip transformers", International Electron Devices Meeting 1998, 1998, pp. 531-534.

13. S. S. Mohan, "The design modeling and optimization of on-chip inductor and transformer circuits", 1999.

14. C Alonso, "Contribution à l'optimisation, la gestion et le traitement de l'énergie", Université Paul Sabatier Toulouse III, 2003.

15. X. Margueron"Elaboration sans prototypage du circuit équivalent des transformateurs de type planar", Université Joseph Fourier, 2006.

16. R. Thüringer "Characterization of Integrated Lumped Inductors and Transformers", Wien, 2002.

17. A. Weisshaar. "Analysis and Modeling of Monolithic On- Chip Transformers on Silicon", Oregon State University, 2005.

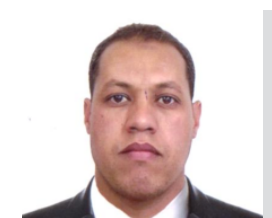

Abdeldjebbar Abdelkader, Diploma in Electrical Engineer 1997, Diploma of magister in plasma 2009, Student in the doctorate from 2010 to date 